\title{
LITERATURA E CONSUMO: UMA LEITURA DO CLÁSSICO VIDAS SECAS
}

\section{Literature and consumption: an approach of the classic Vidas Secas}

\section{Literatura y consumo: lectura del clásico Vidas Secas}

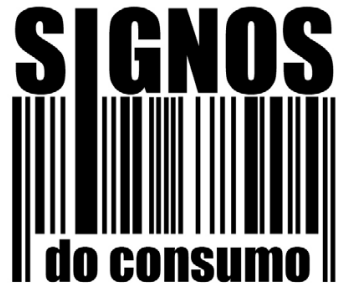

artigo

\author{
João Anzanello Carrascoza \\ Universidade de São Paulo, São Paulo, Brasil. \\ Professor da Escola de Comunicações e Artes da Universidade de São Paulo, onde fez mestrado e doutorado \\ em Ciências da Comunicação. É docente também do Programa de Pós-Graduação em Comunicação e Práticas \\ do Consumo da Escola Superior de Propaganda e Marketing. \\ E-mail: jcarrascoza@espm.br
}

RESUMO A cena midiática é constituída por um sem-número de discursos do consumo. Seguindo o conceito de retextualização de Bettetini, podemos retirar um texto (materialidade do discurso) de seu domínio original e transportá-lo para outro. Assim como Benjamin se vale dos poemas de Baudelaire para investigar o surgimento da sociedade de massa, discutimos o consumo e suas relações com a comunicação, por meio do romance Vidas secas, de Graciliano Ramos. Conceitos da Análise do Discurso de linha francesa serão mobilizados em nossa discussão.

PALAVRAS-CHAVE Vidas secas, Discurso, Consumo, Retextualização.

\begin{abstract}
The media landscape is constituted by innumerable consumption discourses. Following Bettetini's concept of retextualization, we can remove a text (materiality of the discourse) from its original domain and transfer it to another. Like Benjamin uses Baudelaire's poems in order to investigate the emergence of mass society, we discuss consumption and its relationships to communication, by means of Graciliano Ramos' novel Vidas Secas [Barren Lives]. Concepts of the French Discourse Analysis will be mobilized in our discussion.
\end{abstract}

KEYWORDS Vidas Secas, Discourse, Consumption, Retextualization.

RESUMEN La escena mediática está constituida de un sinnúmero de discursos del consumo. Siguiendo el concepto de retextualización de Bettetini, podemos retirar un texto (materialidad del discurso) de su dominio original y transportarlo a otro. Así como Benjamin se vale de los poemas de Baudelaire para investigar el surgimiento de la sociedad de masas, pretendemos discutir el consumo, sus relaciones con los medios de comunicación, mediante la novela Vidas secas, de Graciliano Ramos. En nuestra discusión serán movilizados conceptos del Análisis de Discurso de línea francesa.

PALABRAS CLAVE Vidas secas, Discurso, Consumo, Retextualización. 


\section{UMA INTRODUÇÃO POR MEIO DOS CLÁSSICOS}

Os estudos de Bakhtin (1979) sobre a linguagem abriram caminho para o entendimento do discurso como uma dispersão de textos sociais no avançar da História. O próprio termo "discurso", nos lembra Orlandi (2005, p. 15), traz em si a ideia de curso, de percurso, algo em contínuo movimento. Seguindo os preceitos da Análise de Discurso, sabemos que os textos são fatos discursivos. É neles que a discursividade se materializa. Portanto, é por meio de um ou vários textos enunciados que podemos analisar o discurso.

O dialogismo é elemento constituinte e determinante do discurso, e na esfera discursiva os textos se entrelaçam, atraem-se e se repelem, significam e se ressignificam. A intertextualidade é explorada como estratégia de enunciação, visando produzir empatia entre enunciador e enunciatário em virtude de conteúdos culturais por ambos partilhados.

Assim como existe esse diálogo interno de textos, há também a transposição de um texto de seu domínio original para outro domínio, visando também a uma interação discursiva. Bettetini (1996), estudando a linguagem audiovisual, denominou tal deslocamento de retextualização.

Nosso objetivo neste artigo é retextualizar o romance Vidas secas, de Graciliano Ramos, para o estudo do consumo e da comunicação. Retiramos esse clássico de seu domínio, a arte literária, e o levamos para o domínio científico. Numa de suas tentativas de definir os clássicos, Calvino (2001, p. 11) afirma que

são aqueles livros que chegam até nós trazendo consigo as marcas das leituras que precederam a nossa e atrás de si os traços que deixaram na cultura ou nas culturas que atravessaram (ou mais simplesmente na linguagem ou nos costumes).

Dois casos, entre outros, de retextualizações de obras literárias para o estudo das práticas de consumo, são exemplares do tipo de acoplamento analítico que pretendemos aqui.

O primeiro, obra já clássica sobre a modernidade, é a leitura de Benjamin dos poemas de Baudelaire, elemento-chave em seu pensamento filosófico. Em Passagens, Benjamin (2007) estuda a cenografia histórica do século XIX, na qual Paris, a cidade-vitrine, oferece abundantemente as mercadorias do mundo inteiro. Baudelaire a tematiza em Les fleurs du mal, sobretudo, no Spleen de Paris, com sua galeria de gente (transeuntes, saltimbancos, operários, mendigos) e seus espaços elegantes ou subterrâneos (ruas, bulevares, cafés, bordéis). A prosa de Baudelaire nesse spleen revela a "passagem" da cidade de Paris para metrópole, de seu tempo de "flores" para uma nova era, do "mal" (MATOS, 2008).

O segundo exemplo, focado nas raízes históricas da cultura do consumo, é a retextualização de Schudson (1986) do romance Sister Carrie, de Theodore Dreiser. A protagonista Caroline Meeber (Sister Carrie) parte da pequena cidade de Midwestern para Chicago em busca de fortuna. Nas primeiras páginas da história, Schudson identifica a nova sociedade (do consumo) que se estabelecia nos Estados Unidos. Carrie faz a viagem de trem, meio de transporte de um mundo moderno, que ela ingressa logo ao embarcar. $O$ sentimento de Carrie ao caminhar pelas ruas de Chicago, o cotidiano de seu trabalho numa loja de departamentos - que, assim como as ruas e a estação de trem, tornaram-se um novo tipo de local público -, os anúncios nos jornais (que divulgavam os bens disponíveis e seus preços) e demais detalhes da trama são índices que 
Schudson explora para investigar os primórdios da cultura do consumo na sociedade norte-americana.

Pois bem, nossa escolha recaiu sobre Vidas secas, história de uma família de retirantes nordestinos (o vaqueiro Fabiano, sua mulher sinha Vitória, seus dois filhos e a cachorra Baleia). É a obra de Graciliano Ramos, segundo Álvaro Lins (2001, p. 153), que

contém maior sentimento da terra nordestina, daquela parte que é áspera, dura e cruel, sem deixar de ser amada pelos que a ela estão ligados teluricamente. O que impulsiona os seres desta novela, o que lhes marca a fisionomia e os caracteres, é o fenômeno da seca.

A guiar-nos pelo seu próprio título, o livro não se mostraria muito produtivo para nossa retextualização, há muitas obras de ficção, brasileiras e estrangeiras, que, em princípio, poderiam ser mais frutíferas. Mesmo num exame superficial, algumas delas já revelam questões centrais, atinentes ao tema e promissoras para a discussão proposta.

No âmbito dos clássicos em língua estrangeira, por exemplo, a compulsão pelas compras, advinda da ascensão social, da protagonista de Madame Bovary, de Flaubert (1993), é consensual pela crítica literária - e, de saída, nos conduziria a uma rica investigação. Assim como $O$ paraíso das damas, romance de Émile Zola (2008), que, não por acaso, foi recentemente retextualizado para o estudo do surgimento da sociedade de consumo em Paraíso do consumo: Émile Zola, a magia e os grandes magazines, de Everardo Rocha, Marina Frid e William Corbo (2016). Igualmente, $O$ grande Gatsby, de Scott Fitzgerald (2013) - no qual um indivíduo pobre, Jay Gatsby, modelo de self-made man, torna-se, com o correr dos anos, um recluso milionário -, permite-nos uma larga discussão sobre o consumo e suas ritualizações, se considerarmos o cenário de festas, animadas pelo ritmo do jazz, pulsante no enredo desse romance: a sociedade norteamericana dos anos 1920. Já As coisas: uma história dos anos sessenta, de George Perec (2012), traz a história de Jerôme e Sylvie, jovem casal que, a um só tempo, pleiteia uma vida contrária às convenções sociais e o desejo de consumir bens (em geral) que lhes daria distinção. Em muitos trechos da obra, como este, a seguir, em que o narrador esclarece o contexto no qual os personagens estão inseridos (ainda que possamos constatar um entendimento restrito do consumo, que, inclusive, poderia gerar um vetor de estudo), encontramos pontos de relevância para o debate em questão:

No mundo deles, era quase regra desejar sempre mais do que se podia comprar. Não eram eles que tinham decretado isso, era uma lei da civilização, um dado de fato, de que a publicidade em geral, as revistas, a arte das vitrines, o espetáculo da rua, e até, sob certo aspecto, o conjunto das produções comumente chamadas culturais eram as expressões mais adequadas. (PEREC, 2012, p. 37-38)

Outra passagem, entre tantas, demonstra que tal romance daria uma alentada investigação sobre as mudanças sociais proporcionadas pelas novas práticas de consumo:

Tudo era novo. Sua sensibilidade, seus gostos, seu lugar, tudo os levava para coisas que eles tinham sempre ignorado. Prestavam atenção em como os outros estavam vestidos; observavam nas vitrines os móveis, os objetos de decoração, as gravatas: sonhavam diante dos anúncios das agências imobiliárias. (Ibidem, p. 29) 
Quanto a obras literárias de autores brasileiros, uma rápida pesquisa nos aponta ao menos uma dezena de obras, desde as publicadas na segunda metade do século XIX até as primeiras duas décadas do século XX, como as Memórias póstumas de Brás Cubas, de Machado de Assis (1997) e seu narrador que, "com a pena da galhofa e a tinta da melancolia”, não hesitou em tematizar os hábitos de consumo da elite carioca, a "falsa" mobilidade social no país, além de sua busca pela fama com o lançamento do emplasto anti-hipocondríaco, que levaria ao mundo seu nome impresso na embalagem. Em tempos recentes, podemos citar $O$ rei do cheiro, de João Silverio Trevisan (2009), cuja narrativa evolui plasmando o estilo dos meios de comunicação, o rádio quando o personagem principal nasce numa família pobre, e a televisão depois que ele se torna um rico empresário do ramo de cosméticos, o "rei do cheiro", revelando, ao longo do enredo, o conflito entre os discursos midiáticos, suas estratégias de produção e seu consumo pela sociedade. Da mesma forma, as diversas obras de Férrez, como Capão Pecado (2013) e Os ricos também morrem (2017), que "recriam" o universo da periferia paulista e seus diferentes hábitos de consumo, entre outras desse autor, deixam entrever já numa primeira mirada muitas possibilidades de analisarmos o consumo simbólico e de materialidades.

No entanto, tendo feito uma recente releitura de Vidas secas, a propósito das homenagens pelos 120 anos do nascimento de seu autor, e diante desta outra afirmação de Calvino (2001, p. 15), de que "é clássico aquilo que persiste como rumor mesmo onde predomina a atualidade mais incompatível”, decidimos elegê-la para este desafio.

Motivou-nos, também, um artigo de Maria Aparecida Baccega (2011), decana do Programa de Pós-Graduação em Comunicação e Práticas de Consumo da Escola Superior de Propaganda e Marketing em São Paulo (ESPM-SP), sobre as relações entre comunicação e consumo, no qual a autora, apoiando-se em Canclini, aproxima o conceito de consumo à cidadania $\mathrm{e}$ ilustra o direito do cidadão de ter conhecimento (e acesso) a seus direitos com um trecho de Vidas secas, o primeiro em que sinha Vitória demonstra o desejo de possuir uma cama igual à do seu Tomás da bolandeira.

Baccega (2011) faz uma breve, mas perspicaz, reflexão a partir desse anseio da personagem, manifestado em outras passagens do romance, como se o próprio narrador, pela repetição, estivesse se conscientizando de tal direito:

O livro mostra que sequer a um teto e água - que dirá a uma boa cama - sinha Vitória teve acesso. E muito menos a uma cama de couro, cuja posse se restringia ao dono da bolandeira. O objeto que propicia um conforto maior, desejo da mulher, é ponto de chegada de um processo de conhecimento que vem se desenvolvendo através das gerações. Pertence a todos enquanto objeto síntese do alcançado até ali pela "tecnologia" do conforto. Esse também é o ponto de partida para a continuidade do processo de conhecimento que construirá outros muitos e muitos objetos, os quais todos deveriam poder consumir. É legítimo. O que não é legítimo é a segregação. (Ibidem, p. 27-28)

Não obstante a relevância desse trecho do romance de Graciliano Ramos e a sua associação, feita por Baccega, ao direito de o sujeito contemporâneo consumir bens materiais e simbólicos, o que também faz dele um cidadão e lhe assegura sentido de pertencimento, o excerto é apenas pontual e não consiste numa retextualização, mas numa citação. 
Inspirando-nos neste artigo fundador de Baccega, um dos primeiros e mais esclarecedores no processo de constituição do campo "comunicação e consumo", e prestando um tributo a ela, objetivamos aqui alargar os limites dessa articulação primeva, trazendo à luz outros aspectos de Vidas secas pelos quais é possível abordar o estudo das práticas de consumo.

\section{O CONSUMO: OBJETO DE ESTUDO CONSUMADO}

Vidas secas foi escrito em quadros, cada capítulo tem sua ação autônoma, podendo ser lido de forma independente, mas se articulando com as demais por meio de suturas narrativas. Álvaro Lins (2001, p. 152) afirma que cada capítulo possui "um valor literário tão indiscutível, aliás, que se poderia escolher qualquer um, conforme o gosto pessoal, para as antologias”. Não por acaso assim o fez Italo Moriconi, escolhendo o capítulo "Baleia”, centrado na cachorra da família, para integrar a sua coletânea Os cem melhores contos brasileiros do século (2000).

O livro começa com o capítulo "Mudança”, no qual a família, sedenta e faminta, atravessa durante horas a caatinga rala, à procura de sombra, em meio a ossadas de bichos mortos. Os caminhos cheios de espinhos e seixos, a lama seca e rachada escaldando os pés, o voo negro dos urubus sobre suas cabeças são signos vivos da morte. Na véspera, eram seis os viventes, pois seguia com eles também um papagaio. Mas, como a fome apertara e não havia sinal de comida, sinha Vitória "resolvera [...] aproveitá-lo como alimento" (RAMOS, 2001, p. 11), enganando a fome de todos, inclusive a da cachorra, a quem coubera os pés, a cabeça e os ossos da ave.

Esse episódio inicial do romance nos leva imediatamente a Raymond Williams (1976 apud FEATHERSTONE, 1995, p. 41), ao assinalar que um dos primeiros usos do termo "consumir" significava "destruir", "esgotar". Curiosamente, o oposto a certa estereotipia vigente não apenas na esfera corriqueira, mas também no âmbito acadêmico, nos quais "consumir costuma ser associado a gastos inúteis e compulsões irracionais" (CANCLINI, 1995, p. 51). Citando Marx, Baccega (2011, p. 35) diz que "a necessidade pode estar presente no consumo, mas é também por ele reconfigurada, ressignificada. A fome é a fome, mas satisfazê-la com garfo e faca é bem diferente de satisfazê-la com as mãos”.

Como se num ato de compensação, no dia seguinte é a cachorra Baleia que adia a morte da família, trazendo nos dentes um preá. Era uma caça miúda, mas, como enuncia o narrador, Fabiano, líder do grupo, ele queria viver. E sinha Vitória igualmente, tanto que se põe a beijar "o focinho de Baleia, e como o focinho estava ensanguentado, lambia o sangue e tirava proveito do beijo" (RAMOS, 2011, p. 14). O sujeito histórico se relaciona com o sujeito consumidor pela sua cultura. Para a mulher do vaqueiro, o gosto do viver sabe a sangue.

E, mesmo exausta pela caminhada, sinha Vitória vai externar seu desejo de repousar numa cama como a de seu Tomás da bolandeira, e não mais sobre um leito improvisado de varas. Seu Tomás também fugira com a seca, a bolandeira estava parada, mas a mulher, uma vez viva, continuava a desejar uma cama de verdade. Noutro capítulo de Vidas secas, numa das páginas mais comoventes da literatura brasileira, a cachorra Baleia, atingida pelos tiros da espingarda de pederneira de Fabiano, agoniza e, em seus estertores, não desejava senão dormir e sonhar com um mundo cheio de preás gordos e enormes (Ibidem, p. 91).

Em numerosos trechos do romance há conexões entre o consumo e o estilo de vida dos personagens, mas escolhemos o episódio em que a 
família, já vivendo numas terras onde havia chegado, e onde Fabiano servia ao dono, fazendeiro, dirige-se à cidade para ver os festejos de Natal. O vaqueiro incumbira sinha Terta de fazer roupas para ele e os filhos, mas como comprara tecido em quantidade insuficiente, "as roupas tinham saído curtas, estreitas e cheias de emendas” (RAMOS, 2001, p. 63).

Fabiano, contudo, “tentava não perceber essas desvantagens”, ao mesmo tempo em que "sinha Vitória, enfronhada no vestido vermelho de ramagens, equilibrava-se mal nos sapatos de salto enorme. Teimava em calçar-se como as moças da rua - e dava topadas no caminho" (Ibidem, p. 71).

Bourdieu (1983, p. 121), em "Gostos de classe e estilos de vidas", lembra-nos que os grupos conferem sentidos distintos a um mesmo objeto e "ainda que se manifeste como universal, a disposição estética se enraíza nas condições de existência particulares”, constituindo a dimensão mais rara e distintiva de um estilo de vida. Então, Fabiano,

ao pisar a areia do rio, notou que assim não poderia vencer as três léguas que o separavam da cidade. Descalçou-se, meteu as meias no bolso, tirou o paletó, a gravata e o colarinho, roncou aliviado. Sinha Vitória decidiu imitá-lo: arrancou os sapatos e as meias, que amarrou no lenço. Os meninos puseram as chinelinhas debaixo do braço e sentiram-se à vontade. (RAMOS, 2001, p. 72)

O grupo assim agiu porque estava ainda no caminho, espaço próximo e similar a seu mundo de árvores amarelas, mas, ao atingir um riacho, nas cercanias da cidade, arruma-se novamente, recongraçase, embora, naqueles trajes, seriam penosas as horas que passariam ali, no povoado em festa.

Fabiano, em especial, comparava-se aos tipos do lugar e se sentia inferior. Por isso, desviava-se deles, "sabia que a roupa nova cortada e cosida por sinha Terta, o colarinho, a gravata, as botinas e o chapéu de baeta o tornavam ridículo" (Ibidem, p. 76). Como não exercia na cidade aquelas "práticas sociais e culturais que dão sentido de pertencimento" (CANCLINI, 1995, p. 22), o vaqueiro se embriaga com aguardente e, livrando-se novamente da roupa que não condiz com seu "estilo" de vida, estira-se no cimento, cobre a cabeça com o chapéu e dorme.

Esse capítulo, que, na opinião de Álvaro Lins (2001, p. 153), destaca-se no romance pelo "poder descritivo e [pela] capacidade de visualização" que o ficcionista logrou com uma "sutileza de tons e de notas psicológicas", revela, em alinhamento com Douglas e Isherwood (2006, p. 16), de que maneira o consumo, visto como um código, ao traduzir muitas de nossas relações sociais, "permite classificar coisas e pessoas, produtos e serviços, indivíduos e grupos".

O consumo não apenas afirma a posição do sujeito na hierarquia social, mas é também - e a conduta de quase "desnudamento" de Fabiano o demonstra -, um campo de contestação social: "ao consumir reproduzimos (sustentamos, desenvolvemos, defendemos, contestamos, imaginamos, rejeitamos) modos de vida específicos, culturalmente significativos” (SLATER, 2002, p. 14).

\section{O CONSUMO COMO SISTEMA CLASSIFICATÓRIO}

Vidas secas nos permite reconhecer, em várias de suas passagens, como o consumo, de fato, traduz-se num sistema de classificação do sujeito e de suas relações, eufóricas ou disfóricas, com o outro. 
No capítulo "Sinha Vitória", dedicado a delinear o perfil da personagem, a mulher do vaqueiro repete seu desejo, exposto no início do livro - trecho citado por Baccega -, de possuir uma cama de lastro de couro, como a de seu Tomás da bolandeira, em substituição a cama de varas na qual o casal dormia.

Ela discute com o marido, tentando convencê-lo de que poderiam economizar para a compra da cama, ou já poderiam tê-la efetuado se ele não tivesse gasto dinheiro com jogo e cachaça - referência aos episódios "Cadeia”, quando o vaqueiro perdera no jogo e fora preso, e "Festa", em que ele se embriagara. Ressentido, em resposta, "Fabiano condenara os sapatos de verniz que ela usava nas festas, caros e inúteis. Calçada naquilo, trôpega, mexia-se como um papagaio, era ridícula” (RAMOS, 2001, p. 41).

O capítulo todo é centrado nos monólogos de sinha Vitória, que se põe a pensar em soluções para conseguir a cama, mas parte essencial de sua inquietação advém desse comentário do marido, levando-a a se recordar do "pobre do papagaio" que fora obrigada a matar: "efetivamente não se acostumara a calçar sapatos, mas o remoque de Fabiano molestara-a. Pés de papagaio. Isso mesmo, sem dúvida, matuto anda assim. Para que fazer vergonha à gente? Arreliava-se com a comparação” (Ibidem, p. 43).

A cachorra vem lhe fazer festa, mas, aborrecida com as palavras do marido, sinha Vitória dá-lhe um pontapé, e a cachorra "se afastou humilhada e com sentimentos revolucionários” (Ibidem, p. 39).

O consumo, vimos com Douglas e Isherwood (2006), permite classificar pessoas e objetos - a cama de seu Tomás da bolandeira é ideal, para sinha Vitória; os sapatos da mulher, para Fabiano, são ridículos. Na via oposta, podemos dizer que o "não consumo" também opera como um código posição que pretendemos discutir amplamente noutra oportunidade.

Outro exemplo dessa codificação do sujeito na sociedade pela via do consumo, encontramos em trechos, como este, em que Fabiano se lembra de seu amigo: "Seu Tomás da bolandeira falava bem, estragava os olhos em cima de jornais e livros, mas não sabia mandar: pedia. Esquisitice um homem remediado ser cortês” (RAMOS, 2001, p. 22). O vaqueiro via o outro, letrado, consumidor de jornais e livros, como alguém importante, pessoa de consideração, e, por vezes, quando conversava com gente na cidade, usava expressões que eram de seu Tomás da bolandeira. É uma tentativa de Fabiano, reproduzindo a linguagem do outro, transferir o capital simbólico (BOURDIEU, 1983) daquele para si.

Sobre Fabiano, inclusive, recai o peso da classificação mais contundente do romance. Por consumir e ser consumido por aquele tipo de vida seca, ele oscilará em se autodefinir: "Fabiano, você é um homem” (RAMOS, 2001, p. 18), "Você é um bicho, Fabiano" (Ibidem, p. 18), "Um homem, Fabiano" (Ibidem, p. 24), “Um bruto, está percebendo?” (Ibidem, p. 95).

Vale lembrar, aqui, que a publicidade, um dos discursos mais marcantes da sociedade de consumo, é também, conforme Rocha (1995, p. 62), um sistema classificador por meio da narrativa mítica: a publicidade "transforma o domínio da produção - onde os produtos são indiferenciados, múltiplos, seriados e anônimos - no domínio do consumo onde o produto tem nome, nobreza, mistério e vida.

No entanto, se "tal como um sistema de classificação totêmico, os anúncios desfazem contradições de diferentes níveis” (Ibidem, p. 61), na esfera da sociabilidade nem sempre o sujeito é capaz de desfazer as diferenças, ainda que, pelo consumo - e pelo "não consumo" -, ele possa contestar, opor-se e desafiar a ordem social. 


\section{O CONSUMO E OS SIGNOS FLUTUANTES}

Calvino (2001, p. 13) sugere que o leitor nunca é indiferente ante um clássico; lê-lo, em verdade, serve para defini-lo em relação à obra e, quando não, como seu contraste. Os estudiosos da comunicação se valem de contribuições vitais da área da linguagem, que aportam teorias sobre aspectos determinantes da dinâmica entre enunciador e enunciatário, e também, obviamente, da mensagem, que só se completa pelo encontro de ambos.

Assim sendo, cabe focarmos elementos constitutivos dos discursos do consumo, já que lidam com signos. Baudrillard (1989), num já clássico ensaio apoiado na semiologia, mostra-nos como o signo e a mercadoria se juntam na sociedade capitalista para a produção da "mercadoriasigno". E, em textos posteriores, como aponta Featherstone (1995, p. 33-34), Baudrillard desloca sua ênfase "da produção para a reprodução, para a reduplicação infinita de signos, imagens e simulações por meio da mídia, abolindo a distinção entre imagem e realidade”.

O capítulo "O menino mais velho", de Vidas secas, ilustra com nitidez esse processo de liquefação de signos e imagens. Nesse "quadro", o narrador se empenha em fazer um retrato do primogênito da família e o faz por meio não de suas ações, mas de seu embate com a linguagem, mais precisamente pela dissociação entre significado e significante da palavra inferno:

Deu-se aquilo porque sinha Vitória não conversou um instante com o menino mais velho. Ele nunca tinha ouvido falar em inferno. Estranhando a linguagem de sinha Terta, pediu informações. Sinha Vitória, distraída, aludiu vagamente a certo lugar ruim demais, e como o filho exigisse uma descrição, encolheu os ombros. (RAMOS, 2001, p. 54)

O capítulo assim se abre, e o menino mais velho, insatisfeito com a resposta da mãe, ronda o pai na sala, tentando interrogá-lo. Fabiano, com a faca, tira-lhe o molde dos pés para fazer uma alpercata e o dispensa, com dureza: "Arreda”. Questionado pelo menino, o pai nada responde; o silêncio, em muitas passagens, é signo da incapacidade de comunicação, o que nos remete à célebre proposição de Wittgenstein (1999): os limites da linguagem de um indivíduo são os limites de seu mundo.

O filho retorna à mãe, insiste mais uma vez, e sinha Vitória, depois de falar em espetos quentes e fogueiras, zanga-se com ele, por se manter ainda inquisitivo, e lhe aplica um cocorote.

A partir daí o capítulo reverbera inteiramente um longo monólogo interior do menino à procura do significado de "inferno". E suas ruminações, seu estreito entendimento das coisas, deslizam para Baleia, com quem ele vai interagir. A cachorra, que o acompanha até a beira da "lagoa vazia", onde ele se esconde para pensar, enseja a seguinte percepção do mundo:

Repousava junto à trempe, cochilando no calor, à espera de um osso. Provavelmente não o receberia, mas acreditava nos ossos, e o torpor que a embalava era doce. Mexia-se de longe em longe, punha na dona as pupilas negras onde a confiança brilhava. Admitia a existência de um osso graúdo na panela, e ninguém lhe tirava esta certeza, nenhuma inquietação lhe perturbava os desejos moderados. Às vezes recebia pontapés sem motivo. Os pontapés estavam previstos e não dissipavam a imagem do osso. (RAMOS, 2001, p. 55) 
O menino tenta contar uma história à cachorra. O narrador do romance aponta, então, outro índice da estreiteza linguística dele, afirmando que "tinha um vocabulário quase tão minguado como o do papagaio que morrera no tempo da seca” (Ibidem, p. 55). E, mais adiante, diz que ele "balbuciava expressões complicadas, repetia as sílabas, imitava os berros dos animais" (Ibidem, p. 59).

Inferno: o menino mais velho queria que aquela "palavra virasse coisa". A mãe se referira a "um lugar ruim, com espetos e fogueiras". Mas, para ele, "todos os lugares eram bons”. Não podia acreditar que um nome tão bonito significasse algo ruim. Aos poucos, contudo, recolhido junto à cachorra, conclui que talvez sinha Vitória dissesse a verdade: o inferno seria um lugar de coisas ruins. E as concebe a partir de sua experiência cultural, a pretérita e aquela havia pouco vivida com seus pais: "as pessoas que moravam lá recebiam cocorotes, puxões de orelhas e pancadas com bainha de faca” (Ibidem, p. 61).

O mesmo ocorre com Baleia que, nas linhas finais desse quadro, abraçada pelo menino - dois signos à procura de significado -, sente o cheiro dele, mas prefere as emanações que vinham da cozinha. Para a cachorra, em chave análoga, "havia ali um osso. Um osso graúdo, cheio de tutano e com alguma carne” (Ibidem, p. 62).

O capítulo traz embutida uma questão associada à flutuação dos signos na sociedade de consumo (a disjunção entre o real e o visual) igualmente importante para nós: a do contexto sócio-histórico. Em Análise de Discurso, define-se "condições de produção" como as circunstâncias da enunciação, os sujeitos e a situação. Segundo Orlandi (2005, p. 34), "só uma parte do dizível é acessível ao sujeito pois mesmo o que ele não diz (e que muitas vezes ele desconhece) significa em suas palavras”.

Em todo discurso, incluindo o do consumo, o esquecimento enunciativo e o esquecimento ideológico reverberam nos sujeitos

para, ao se identificarem com o que dizem, se constituírem sujeitos. É assim que suas palavras adquirem sentido, é assim que eles se significam retomando palavras já existentes como se elas se originassem neles e é assim que sentidos e sujeitos estão sempre em movimento, significando sempre de muitas e variadas maneiras. Sempre as mesmas mas, ao mesmo tempo, sempre outras. (Ibidem, p. 36)

Não gratuitamente o menino mais velho - igual a seu irmão, o menino mais novo - é um personagem sem nome, como se ambos ainda não fossem "significantes” no universo onde habitam, como o são Fabiano, sinha Vitória, sinha Terta e seu Tomás da bolandeira.

Essa anomia nos leva a seu reverso, à nomeação e aos efeitos de sentido por ela produzidos. Vidas secas, também nesse aspecto, conecta-nos com o naming - técnica de dar nomes a produtos de marcas comerciais. $\mathrm{O}$ naming é parte essencial da criação publicitária, sobretudo na sociedade midiática contemporânea, na qual se nota intensa comoditização de mercadorias, obrigando a comunicação de uma marca ser, ela mesma, um diferencial discursivo a seu favor.

O nome batiza a mercadoria, como aponta Rocha (1995), e, uma vez nomeada, assim será conhecida. É a célula-gênese, ponto inaugural de seu discurso. Não obstante as mudanças sociais a que vai enfrentar e a contínua liquefação dos signos, o nome objetiva trazer à marca o sentido de permanência, "já que as imagens se deslocam o tempo todo em torno do nome que é fixo" (FONTENELLE, 2002, p. 250). 
Na Biblioteca Brasiliana Mindlin, onde se encontram os originais de Vidas secas, pode-se constatar que o livro tinha como título "O mundo coberto de penas”, idêntico a um de seus “quadros”, técnica comum, entre os escritores, para dar nome a um livro de contos - a escolha recai na narrativa que melhor representa o todo ali contido. Esse título, no entanto, foi riscado pelo autor, que, sobre ele anotou o novo, com o qual passaria para a história.

Graciliano Ramos, assim, afastou da obra a ideia de que se tratava de um livro de contos, mesmo se entrelaçados tematicamente, com os mesmos personagens, e buscou lhe dar o status de "romance". Sua nomeação vai influenciar tudo o que se escreveu posteriormente sobre a obra, inclusive este artigo. A mercadoria "livro", fabricada nos moldes da indústria cultural, também vai requerer um nome que lhe assegure uma aura.

\section{O CONSUMO POR UMA VISÃO CALEIDOSCÓPICA}

O consumo, como objeto de estudo, permaneceu durante décadas no ostracismo, numa espécie de l1imbo acadêmico, como diz Baccega (2001, p. 28) pelo menos no âmbito dos pesquisadores nacionais.

Mas, o afrouxamento de barreiras entre as ciências humanas e sociais, desencadeado pelas transformações sociais mundo afora, abriu e intensificou as discussões sobre o consumo e suas interfaces com a comunicação, o "consumismo", a sociedade de consumidores, o advento dos "prossumidores".

O Programa de Pós-Graduação em Comunicações e Práticas de Consumo da ESPM-SP foi pioneiro em enfrentar questões clássicas e emergentes na confluência entre a comunicação social e o consumo entendido como fenômeno complexo da/na contemporaneidade. Nos numerosos estudos já realizados sob a rubrica desse programa, que completou um decênio, tornou-se evidente para seus pesquisadores a incapacidade de se investigar o consumo por meio de uma chave única. Vidas secas nos dá pistas de como abordá-lo, o que vem sendo feito nas pesquisas, desde o início desse programa. O livro, já mencionamos, é constituído de capítulos centrados em monólogos interiores, com ação própria, podendo ser lidos em separado dos demais. Apesar de a crítica apontar a falta de uma articulação mais sólida e segura entre os quadros narrativos (LINS, 2001), essa estrutura, que podemos chamar de caleidoscópica, traz desdobramentos impossíveis à história se contados da maneira tradicional, quase sempre linear, dos romances realistas até então canônicos.

Um fato narrado num capítulo ganha novo sentido à luz do capítulo seguinte; um personagem protagonista de um episódio, como Fabiano, ou o menino mais velho, reaparece de forma coadjuvante em outros - e a apreensão, mais plena, de cada uma dessas vidas secas se dá unicamente por meio da leitura obrigatória, multifacetada da obra.

Ainda que falte unidade formal na disposição dos monólogos, em relação à sua substância, ao assunto de seu enredo, o romance "apresenta uma perfeita unidade, uma completa harmonia interior. O drama do primeiro capítulo repete-se no último; e tudo o mais que se encontra entre eles constitui uma matéria de ligação entre os dois episódios semelhantes” (LINS, 2001, p. 153).

De forma similar, a abordagem caleidoscópica do consumo é a única capaz de revelar nuances que o domínio da Antropologia, da Sociologia, 
da Psicologia, da História, da própria comunicação, de modo isolado, não atingiu, por mais profundas que sejam suas discussões. No intuito de investigar algumas das principais representações do consumo, no senso comum e na cultura de massa, e de alargar a discussão, Rocha (2005) propõe uma classificação dessas várias “compreensões” do fenômeno do consumo como hedonista, moralista, natural e utilitária. Em suas conclusões, afirma que é no

jogo mágico, envolvendo confecção de mitos e práticas de rituais, que acontece o consumo, lugar privilegiado para um exercício permanente de classificação que, ao estilo de um sistema totêmico, fornece os valores e as categorias pelos quais concebemos diferenças e semelhanças entre objetos e seres humanos. (Ibidem, p. 137)

Reforça, assim, a necessidade de observá-lo de variadas angulações. É indispensável explorar a multi e a transdisciplinaridade para investigar o consumo (como objeto de estudo), atentando para suas numerosas e ainda desconhecidas interações - pois as zonas de sombra num campo do conhecimento recebem a claridade de outro, e vice-versa, possibilitando inéditas abordagens.

Nesse contexto, como se observando um caleidoscópio, percebemos efeitos de luz que desaparecem se o giramos, e reaparecem com outros matizes se de novo o movemos. Então, algo que se supõe ausente está, em verdade, ali presente à sombra. Daí emerge imediatamente o tema dos não-ditos discursivos, tão importantes quanto os ditos.

Em Vidas secas, à diferença de outros romances que descrevem ostensivamente a paisagem árida do sertão, Graciliano Ramos trabalha com o mínimo de elementos descritivos, "secando" também os contornos dos espaços nos quais o fragmentado enredo, como os vidros coloridos dos caleidoscópios, se delineia. É por isso que encontramos "riqueza" nesta retextualização.

Se podemos ler a obra pelo "sim", pelo que afirma em seus dizeres, também podemos lê-la pelo "não”, pelo que silencia, como explicitado neste poema de Leminski (2013, p. 223):

Ler pelo não, quem dera!

Em cada ausência, sentir o cheiro forte

do corpo que se foi,

a coisa que se espera.

Ler pelo não, além da letra,

vez, em cada rima vera, a prima pedra,

onde a forma perdida

procura seus etcéteras.

Desler, tresler, contraler,

enlear-se nos ritmos da matéria,

no fora, ver o dentro e, no dentro, o fora,

navegar em direção às Índias

e descobrir a América.

Encontramos no romance personagens que se assemelham a bicho (Fabiano e a família), mas também bicho que alcança a condição humana (Baleia). Imaginamos reinar naquela terra o sol avassalador do verão e damos com um episódio como "Inverno". Navegamos em direção às Índias e descobrimos (também) a América. Entramos no território da ficção e damos também com a realidade do consumo. 
Assim, fechando nosso paralelismo, para estudar a parelha comunicação e consumo, é preciso desler, tresler, contraler. Se aquilo que consumimos diz muito sobre nós, aquilo que não consumimos também diz. Os ditos são margeados pelos não-ditos. A arte (retextualizada) é circundada pela ciência.

\section{DE VOLTA AO FUTURO}

Vida secas termina, como no início, com a família em fuga, dessa vez saindo da fazenda e seguindo para o espaço urbano. A circularidade do desfecho pressupõe a continuidade do sofrimento daquelas existências - 0 mundo a recomeçar, sempre igual: "Chegariam a uma terra desconhecida e civilizada, ficariam presos nela. E o sertão continuaria a mandar gente para lá. O sertão mandaria para a cidade homens fortes, brutos, como Fabiano, sinha Vitória e os dois meninos” (RAMOS, 2001, p. 126).

Tal constatação nos remete aos versos de Paul Auster (2013, p. 293):

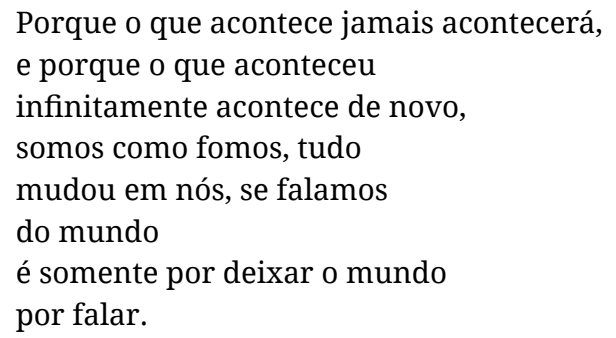

Nas palavras finais do narrador de Vidas secas, contudo, ainda encontramos esperança:

Mudar-se-iam depois para uma cidade, e os meninos frequentariam escolas, seriam diferentes deles. [...] Iriam para diante, alcançariam uma terra desconhecida. Fabiano estava contente e acreditava nessa terra, porque não sabia como ela era nem onde era. Repetia docilmente as palavras de sinha Vitória, as palavras que sinha Vitória murmurava porque tinha confiança nele. E andavam para o sul, metidos naquele sonho. (RAMOS, 2001, p. 125-126)

Uma esperança que nos devolve à reflexão inicial de Baccega (2011, p. 27): aquele sonho pode ser o "ponto de chegada de um processo de conhecimento que vem se desenvolvendo através das gerações", um ponto que nos conduza a um tempo de maior inclusão e menor segregação social. É esse o desejo de Fabiano, tão legítimo quanto a cama sonhada por sua mulher: "os meninos em escolas, aprendendo coisas difíceis e necessárias” (Ibidem, p. 126).

Ao fim, embora tenhamos feito uma imersão em Vidas secas, encontrando terreno exuberante para investigarmos relações entre comunicação e consumo, assim como Fabiano se mostrava contente por desconhecer como era a terra aonde ele e a família chegariam, julgamos que há no clássico de Graciliano Ramos outros aspectos passíveis de aprofundamento nesta e em futuras retextualizações.

Calvino (2001, p. 11) afirma que "um clássico é um livro que nunca terminou de dizer aquilo que tinha para dizer”. Seja sobre sua própria história, seja, podemos acrescentar, sobre o universo da comunicação e do consumo. 


\section{REFERÊNCIAS}

ASSIS, M. Memórias póstumas de Brás Cubas. Rio de Janeiro: Ediouro, 1997.

AUSTER, P. Todos os poemas. São Paulo: Companhia das Letras, 2013.

BENJAMIN, W. Passagens. Belo Horizonte: UFMG, 2007.

BACCEGA, M. A. Inter-relações comunicação e consumo na trama cultural: o papel do sujeito ativo. In: CARRASCOZA, J. A.; ROCHA, R. M. (Orgs.). Consumo midiático e culturas da convergência. São Paulo: Miró, 2011. p. 26-44.

BAKHTIN, M. Marxismo e filosofia da linguagem. São Paulo: Hucitec, 1979.

BAUDRILLARD, J. O sistema dos objetos. 2. ed. São Paulo: Perspectiva, 1989.

BETTETINI, G. La conversación audiovisual. Barcelona: Cátedra, 1996.

BOURDIEU, P. Questões de sociologia. Rio de Janeiro: Marco Zero, 1983.

. Gostos de classe e estilos de vida. In: ORTIZ, P. Pierre Bourdieu. São Paulo: Ática, 1983. p. 82-121.

CALVINO, I. Por que ler os clássicos. São Paulo: Companhia das Letras, 2001.

CANCLINI, N. G. Consumidores e cidadãos: conflitos multiculturais da globalização. Rio de Janeiro: UFRJ, 1995.

DOUGLAS, M.; ISHERWOOD, B. O mundo dos bens. Rio de Janeiro: UFRJ, 2006.

FEATHERSTONE, M. Cultura de consumo e pós-modernismo. São Paulo: Nobel, 1995.

FÉRREZ. Capão pecado. São Paulo: Planeta, 2013.

. Os ricos também morrem. São Paulo: Planeta, 2017.

FITZGERALD, F. S. O grande Gatsby. São Paulo: Leya, 2013.

FLAUBERT, G. Madame Bovary. São Paulo: Nova Alexandria,1993.

FONTENELLE, I. O nome da marca. São Paulo: Boitempo, 2002.

LEMINSKI, P. Toda poesia. São Paulo: Companhia das Letras, 2013.

LINS, A. Valores e misérias das vidas secas. In: RAMOS, G. Vidas secas. 82. ed. Rio de Janeiro: Record, 2001. p. 127-155.

MATOS, O. A cena primitiva: capitalismo e fetiche em Walter Benjamin. In: BACCEGA, M. A. (Org.). Comunicação e culturas do consumo. São Paulo: Atlas, 2008. p. 87-104.

MORICONI, I. (Org.). Os cem melhores contos brasileiros do século. Rio de Janeiro: Objetiva, 2000.

ORLANDI, E. P. Análise de discurso: princípios e procedimentos. 6. ed. Campinas: Pontes, 2005.

PEREC, G. As coisas: uma história dos anos sessenta. São Paulo: Companhia das Letras, 2012.

RAMOS, G. Vidas secas. 82. ed. Rio de Janeiro: Record, 2001.

ROCHA, E. Culpa e prazer: imagens do consumo na cultura de massa. Revista Comunicação, Mídia e Consumo, São Paulo, v. 2, n. 3, p. 123-138, mar. 2005.

ROCHA, E. P. G. Magia e capitalismo: um estudo antropológico da publicidade. São Paulo: Brasiliense, 1995.

ROCHA, E.; FRID, M.; CORBO, W. Paraíso do consumo: Émile Zola, a magia e os grandes magazines. Rio de Janeiro: PUC-Rio; Mauad, 2016.

SCHUDSON, M. Advertising, the uneasy persuasion. New York: Basic Books, 1986.

SLATER, D. Cultura do consumo e modernidade. São Paulo: Nobel, 2002.

TREVISAN, J. S. O rei do cheiro. Rio de Janeiro: Record, 2009.

WITTGENSTEIN, L. Investigações filosóficas. São Paulo: Nova Cultural, 1999.

ZOLA, É. O paraíso das damas. São Paulo: Estação Liberdade, 2008. 